\title{
T3 Stage Finding
}

National Cancer Institute

\section{Source}

National Cancer Institute. T3 Stage Finding. NCI Thesaurus. Code C48728.

A clinical and/or pathologic primary tumor TNM finding usually indicating that the cancer

is locally invasive, without infiltration of adjacent structures. 